\title{
BMJ Open Drivers and strategies for avoiding overuse. A cross-sectional study to explore the experience of Spanish primary care providers handling uncertainty and patients' requests
}

José Joaquín Mira, ${ }^{1,2,3}$ Irene Carrillo, ${ }^{2}$ Carmen Silvestre, ${ }^{4}$ Pastora Pérez-Pérez, ${ }^{5}$ Cristina Nebot, ${ }^{6}$ Guadalupe Olivera, ${ }^{7}$ Javier González de Dios, ${ }^{8,9}$ Jesús María Aranaz Andrés ${ }^{10,11}$

To cite: Mira JJ, Carrillo I, Silvestre C, et al. Drivers and strategies for avoiding overuse. A cross-sectional study to explore the experience of Spanish primary care providers handling uncertainty and patients' requests. BMJ Open 2018;8:e021339. doi:10.1136/ bmjopen-2017-021339

- Prepublication history for this paper is available online. To view these files, please visit the journal online (http://dx.doi. org/10.1136/bmjopen-2017021339).

Received 21 December 2017

Revised 22 April 2018

Accepted 22 May 2018
Check for updates

For numbered affiliations see end of article.

Correspondence to Dr José Joaquín Mira; jose.mira@umh.es

\section{ABSTRACT}

Objectives Identify the sources of overuse from the point of view of the Spanish primary care professionals, and analyse the frequency of overuse due to pressure from patients in addition to the responses when professionals face these demands.

Design A cross-sectional study.

Setting Primary care in Spain.

Participants A non-randomised sample of 2201 providers (general practitioners, paediatricians and nurses) was recruited during the survey.

Primary and secondary outcome measures The frequency, causes and responsibility for overuse, the frequency that patients demand unnecessary tests or procedures, the profile of the most demanding patients, and arguments for dissuading the patient.

Results In all, 936 general practitioners, 682 paediatricians and 286 nurses replied (response rate $18.6 \%)$. Patient requests (67\%) and defensive medicine $(40 \%)$ were the most cited causes of overuse. Five hundred and twenty-two (27\%) received requests from their patients almost every day for unnecessary tests or procedures, and $132(7 \%)$ recognised granting the requests. The lack of time in consultation, and information about new medical advances and treatments that patients could find on printed and digital media, contributed to the professional's inability to adequately counter this pressure by patients. Clinical safety $(49.9 \%)$ and evidence $(39.4 \%)$ were the arguments that dissuaded patients from their requests the most. Cost savings was not a convincing argument (6.8\%), above all for paediatricians (4.3\%). General practitioners resisted more pressure from their patients $\left(\mathrm{x}^{2}=88.8, \mathrm{P}<0.001\right.$, percentage difference $(P D)=17.0)$, while nurses admitted to carrying out more unnecessary procedures $\left(x^{2}=175.7\right.$, $\mathrm{P}<0.001, \mathrm{PD}=12.3$ ).

Conclusion Satisfying the patient and patient uncertainty about what should be done and defensive medicine practices explains some of the frequent causes of overuse. Safety arguments are useful to dissuade patients from their requests.

\section{Strengths and limitations of this study}

$\Rightarrow$ The strengths of the present study include its large sample of providers working on an ample number of Spanish primary care health organisations. This sample included general practitioners, paediatricians and nurses.

$\Rightarrow$ Frequency and causes of overuse were analysed beside the profile of the most demanding patients, and arguments to dissuade the patient.

$\Rightarrow$ Although data are derived only from Spain, it is likely to be representative of the rest of the health systems where general practitioners are the gatekeepers.

$\Rightarrow$ The study did not based on a random selection of participants. A limited number of males in the cases of paediatrics and nursing were involved even though their number is proportional to that of their presence within these professional groups. The data correspond to a health model funded by taxes.

\section{INTRODUCTION}

Among the causes of lack of quality are the incorrect use of diagnostic or therapeutic resources due to medical errors, ${ }^{12}$ underuse $^{3}$ and overuse. ${ }^{4}$

Overuse is understood to be the provision of healthcare when lacking evidence or when the potential benefits from the procedure or treatment do not outweigh its risks. ${ }^{5}$ Overuse of diagnostic and therapeutic resources is present in all specialties, all health systems ${ }^{46}$ and at all care levels, ${ }^{7}$ and it represents a threat to patient safety and the sustainability of health systems. ${ }^{8}$ Reducing overuse in primary care is particularly relevant when the general practitioner is the gatekeeper of the health system. However, in many countries the actual pattern of overuse remains virtually unknown. ${ }^{9}$ 


\section{Causes of overuse}

The immediate causes of overuse include ${ }^{10-15}$ insufficient updating of knowledge by professionals, defensive medicine, the custom of doing things that have always been done, lack of time in consultation, inadequate incentives, influence by the pharmaceutical industry and inadequate communication with patients. Patients requesting diagnostic tests ${ }^{91617}$ or treatments based on personal beliefs or from information obtained by other patients or from the internet ${ }^{91819}$ have been also identified as a cause of overuse.

Patients in primary care usually request diagnostic tests, referrals to specialists and medications, more frequently antimicrobials and for reducing pain. $^{9}{ }^{20}$ These requests generate dissatisfaction and make professionals uncomfortable ${ }^{21}$ because they call their clinical expertise into question, ${ }^{22}$ and this affects the quality of the relationship with the patient. Primary care physicians accept and handle the relationship with the patient better in the case of requests for tests and referrals to specialists than when the patient requests certain medications. ${ }^{23}$ However, they often manifest in a desire to fulfil their patients' expectations, increasing overuse. ${ }^{24}$ Other drivers of medical overuse from a primary care perspective also includes the lack of communication skills or medical work experience, insufficient time during consultation and fear of malpractice. ${ }^{92425}$

\section{Questions to be answered}

There is little research on the role of the patient and the professional in overuse, and most of it has been carried out in the USA, which has an organisational environment different from the models based on a national health system. ${ }^{11}$ The little data there are suggest that medical recommendations to reduce overuse are difficult to follow and difficult for patients to accept, ${ }^{26}$ although research is needed to discern the profile of patients prone to accept or refuse these recommendations. It is hoped that the organisational model of the provision of healthcare has a direct influence on overuse. In the case of models where the primary care physician is the gatekeeper, one could expect greater pressure on this professional. $^{27}$

\section{Objectives}

This study identified the sources of overuse from the point of view of Spanish primary care professionals, and analysed the frequency of overuse due to pressure from patients in addition to the responses when professionals face these demands. Specifically, this study searched for answers to the following questions:

Perceived causes and responsibility of overuse from the primary care front-line providers.

Patient profiles and their requests and responses from healthcare professionals and how they dissuade patients.

\section{METHOD}

A cross-sectional study was conducted based on an online survey directed at a group of primary care professionals in Spain: general practitioners, paediatricians and nurses. The field study took place between March and July 2017.

\section{Setting}

In Spain, primary care provides stepped care based on the right care at the right place at the right time, balancing quality and costs. This system strengthens the gatekeeper role of general practitioners (and paediatricians in the case of children). They are the ones who make diagnostic and therapeutic decisions in every case, which includes the possibility of referrals to other specialists at hospitals.

Spanish territory is divided into health districts, and in turn, these are divided into health zones. Each zone contains a health centre that is responsible for providing healthcare for that territorial demarcation, with general practitioners, paediatricians and nurses. One health district attends to an average of some 250000 residents. The composition of professionals on primary health teams varies depending on the population of the health zone (ratio around 1300 residents per general practitioner ${ }^{28}$ and 1029 residents between the ages of 0 and 14 years per paediatrician). ${ }^{29}$ The number of nurses is similar to that of general practitioners and paediatricians. ${ }^{30}$

\section{Materials}

The scope of the survey was based on the instrument employed by the ABIM (American Board of Internal Medicine) Foundation. ${ }^{11}$ Seven blocks of questions were analysed and 28 questions formulated. Specifically analysed were the causes and responsibility of unnecessary overuse, tests or procedures demanded most by patients, the profile of the patient who insists on these requests, the frequency of receiving requests and the frequency that the professional orders them, the arguments employed for dissuading the patient and the extent to which they succeed, and the reactions by the patient to the professional's refusal. A pilot test on comprehending the questions was carried out with six professionals whose profiles were similar to those who participated in the study. Proposals for changes to the wording or response scales were incorporated into the final draft of the questions.

\section{Participants}

A non-randomised sample of primary care providers was surveyed. To carry out this survey on a population of 63753 professionals (28294 general practitioners, 6251 paediatricians and 29208 nurses), a minimal sample of 2201 professionals from all groups (general practitioners, paediatricians and nurses) was determined, considering a $1 \%$ error, a confidence level of $95 \%, p=q=0.50$ and a response rate of $20 \%$.

The field study was conducted in collaboration with the health services of Andalucía, Aragón, Madrid, Navarra, and the Comunidad Valenciana, the Spanish Association of Primary Care Paediatrics, the Spanish Society of 
Outpatient and Primary Care Paediatrics, the Illustrious Official College of Physicians of Valencia, the Council of Nursing of the Valencian Community, and the Spanish Society of General and Family Practitioners. These organisations invited their associates to participate in this study, and sent a total of 12787 emails (88\% of the emails were expected to be opened). They explained the study's scope to each group of primary caregivers, its voluntary nature and the guarantees for the confidentiality of their responses, instructions on how to respond; it also provided a link to a Google Forms page where they could respond. A reminder to motivate responses was given.

\section{Non-eligible participants}

The responses from professionals who indicated that they worked at hospitals or other centres different from primary care were excluded. Also, participants were excluded when three or more questions were not answered. Incomplete questionnaires were not considered during the statistical analysis.

\section{Patient and public involvement}

Patients and public were not involved in this study.

\section{Potential sources of bias}

The reasons why some professionals answered the survey and others did not could affect the meaning of their answers. A sampling error of $1 \%$ was defined to reduce its effect.

\section{Statistical methods}

The answers by physicians, paediatricians and nurses were compared. Professional experience and gender were used to compare the responses of each group and to assess their trends. The opinions of these professionals working in the public or private sectors were compared.

Data analysis was completed using descriptive and inferential descriptive statistics, with $\chi^{2}$ and analysis of variance to establish relationships between qualitative variables, and between qualitative and quantitative variables, respectively. The overuse experience was distinguished by different types of providers. The null hypothesis was rejected when $\mathrm{P}<0.05$.

\section{RESULTS}

In all, 2098 professionals provided complete responses (response rate $18.6 \%$ ), achieving $95.3 \%$ of the expected responses. Of these, 194 indicated they were working in hospitals, so the responses from 1904 professionals (936 general practitioners, 682 paediatricians and 286 nurses) (table 1) were coded and analysed. Most of these, $1190(62.5 \%)$, were recruited by invitation from professional societies, and $714(37.5 \%)$ were invited by their health services. There were 1816 (95.4\%) working at health centres from the Spanish public health system, with the remainder either working in private health or practising in both professional fields. Three-quarters of the sample $(n=1432,75.2 \%)$ had more than 15
Table 1 Description of the sample of professionals whose responses were analysed

\begin{tabular}{|c|c|c|c|}
\hline & $\begin{array}{l}\text { General } \\
\text { practitioners } \\
(n=936)\end{array}$ & $\begin{array}{l}\text { Paediatricians } \\
(n=682)\end{array}$ & $\begin{array}{l}\text { Nurses } \\
(n=286)\end{array}$ \\
\hline & N (\%) & N (\%) & N (\%) \\
\hline \multicolumn{4}{|c|}{ Professional experience } \\
\hline$\leq 5$ years & $38(4.1)$ & $65(9.5)$ & $20(7)$ \\
\hline $\begin{array}{l}\text { Between } 6 \\
\text { and } 15 \text { years }\end{array}$ & $142(15.2)$ & $166(24.3)$ & $41(14.3)$ \\
\hline $\begin{array}{l}\text { Between } 16 \\
\text { and } 29 \text { years }\end{array}$ & $470(50.2)$ & 268 (39.3) & $129(45.1)$ \\
\hline $\begin{array}{l}\text { More than } \\
30 \text { years }\end{array}$ & $286(30.6)$ & $183(26.8)$ & $96(33.6)$ \\
\hline \multicolumn{4}{|l|}{ Gender } \\
\hline Male & $429(45.8)$ & $196(28.7)$ & $60(21)$ \\
\hline Female & $507(54.2)$ & $486(71.3)$ & $226(79)$ \\
\hline \multicolumn{4}{|c|}{ Area of professional practice } \\
\hline Public system & $892(95.3)$ & $638(93.5)$ & $286(100)$ \\
\hline $\begin{array}{l}\text { Private or } \\
\text { both }\end{array}$ & $44(4.7)$ & $44(6.5)$ & $0(0)$ \\
\hline \multicolumn{4}{|c|}{ Belongs to (institution or organism) } \\
\hline $\begin{array}{l}\text { Public health } \\
\text { system }\end{array}$ & $317(33.9)$ & $138(20.2)$ & $259(90.6)$ \\
\hline CECOVA & - & - & $27(9.4)$ \\
\hline SEMG & $464(49.6)$ & - & - \\
\hline $\begin{array}{l}\text { Illustrious } \\
\text { Official } \\
\text { College of } \\
\text { Physicians of } \\
\text { Valencia }\end{array}$ & $155(16.6)$ & $62(9.1)$ & - \\
\hline AEPap & - & $280(41.1)$ & - \\
\hline SEPEAP & - & 202 (29.6) & - \\
\hline \multicolumn{4}{|c|}{$\begin{array}{l}\text { AEPap, Spanish Association of Primary Care Paediatrics; CECOVA, } \\
\text { Council of Nursing of the Valencian Community; SEMG, Spanish } \\
\text { Society of General and Family Practitioners; SEPEAP, Spanish Society } \\
\text { of Outpatient and Primary Care Paediatrics. }\end{array}$} \\
\hline
\end{tabular}

years of professional experience. Men in paediatrics and nursing, in addition to the professionals from the private sector, were under-represented in a manner similar to their proportion in the make-up of primary care in Spain. ${ }^{30}$

\section{Causes of overuse}

The reasons that general practitioners and paediatricians gave as being more directly responsible for inappropriate overuse were patient (or guardian) insistence and the need to attain greater safety or control over the process (table 2). Male general practitioners, compared with their female counterparts, showed a greater tendency to justify inappropriate overuse on the grounds of satisfying the patient $\left(\mathrm{x}^{2}=5.2, \mathrm{P}=0.024\right.$, percentage difference $(\mathrm{PD})=6.1)$. As causes of overuse, less experienced general practitioners indicated following regulations $\left(\mathrm{x}^{2}=14.4, \mathrm{P}=0.002, \mathrm{PD}=19.1\right)$, making the patient 
Table 2 Reasons for ordering an unnecessary test or carrying out an unnecessary medical procedure

\begin{tabular}{|c|c|c|c|}
\hline & $\begin{array}{l}\text { General practitioners } \\
(n=936)\end{array}$ & $\begin{array}{l}\text { Paediatricians } \\
(\mathrm{n}=682)\end{array}$ & $\begin{array}{l}\text { Total } \\
(n=1618)\end{array}$ \\
\hline & $\mathbf{N}(\%)$ & $\mathbf{N}(\%)$ & N (\%) \\
\hline Due to lack of time for patient consultation & $418(44.7)$ & $198(29.0)$ & $616(38.1)$ \\
\hline To gain greater control and safety of the case & $359(38.4)$ & $291(42.7)$ & $650(40.2)$ \\
\hline To avoid a future demand & $200(21.4)$ & $92(13.5)$ & $292(18.1)$ \\
\hline To satisfy the patient & $196(20.9)$ & $92(13.5)$ & $288(17.8)$ \\
\hline To avoid a claim & $177(18.9)$ & $80(11.7)$ & $257(15.9)$ \\
\hline Out of respect for the patient's decisions & $132(14.1)$ & $130(19.1)$ & $262(16.2)$ \\
\hline
\end{tabular}

feel satisfied with the care received $\left(\mathrm{x}^{2}=11.0, \mathrm{P}=0.011\right.$, $\mathrm{PD}=21.2)$ and avoiding possible claims $\left(\mathrm{x}^{2}=8.6, \mathrm{P}=0.035\right.$, $\mathrm{PD}=14.8)$. When comparing the opinions of general practitioners who only worked within the public sector with those who worked in both public and private, it was observed that the former tended to consider the lack of time in consultation as a reason for overuse more frequently $\left(\mathrm{x}^{2}=13.1, \mathrm{P}=0.001, \mathrm{PD}=27.8\right)$. However, for the latter (with activities in both the public and private systems), avoiding a claim by patients was more important $\left(\mathrm{x}^{2}=21.2, \mathrm{P}=0.001, \mathrm{PD}=27.9\right)$, and they more frequently considered that the practice guides they used as reference were obsolete $\left(\mathrm{x}^{2}=6.8, \mathrm{P}=0.009\right.$, $\mathrm{PD}=6.6)$. Paediatricians who combined activities in both sectors reported more frequently on the difficulties of dissuading the guardian and making him/her see that the procedures requested for the child were unnecessary $\left(\mathrm{x}^{2}=4.6, \mathrm{P}=0.037, \mathrm{PD}=13.8\right)$. General practitioners $\left(\mathrm{x}^{2}=11.8, \mathrm{P}=0.001, \mathrm{PD}=25.0\right)$ and paediatricians $\left(\mathrm{x}^{2}=5.9\right.$, $\mathrm{P}=0.018, \mathrm{PD}=18.7$ ) who only worked in the public sector felt more pressured by patients than those who practised in both sectors.

\section{Responsibility for overuse}

The responsibility for overuse was assigned to, in order, the patients' relatives, the mass media, the professionals themselves, health pages on the internet and defensive medicine practices (table 3). Male professionals attributed the responsibility for overuse of resources due to pressure by patients more directly on health service senior management $(\mathrm{F}=4.3, \mathrm{P}=0.038,95 \% \mathrm{CI}-0.01$ to 0.53). Those solely working in the public health system (as opposed to those who also worked in private practice) held the media ( $\mathrm{F}=6.4, \mathrm{P}=0.011,95 \%$ CI 0.20 to 0.52 ) and patients' relatives $(\mathrm{F}=4.5, \mathrm{P}=0.03,95 \% \mathrm{CI}-0.07$ to 1.06$)$ more directly accountable. No cross-effects from the interaction of these variables were observed.

\section{Pressure by patients and responses from professionals}

Only $31(1.6 \%)$ of those surveyed said that they had not received any requests from patients (more frequent among professionals with more than 15 years of experience), while $103(5.4 \%)$ said that they received requests like these from patients every day (normally younger professionals). General practitioners were those who claimed to be under greater pressure to carry out unnecessary tests or procedures $\left(\mathrm{x}^{2}=88.8, \mathrm{P}<0.001, \mathrm{PD}=17.0\right)$. However, it was the nurses who admitted to carrying out these types of unnecessary procedures more frequently; paediatrics did so the least $\left(\mathrm{x}^{2}=175.7, \mathrm{P}<0.001, \mathrm{PD}=12.3\right)$ (table 4 ).

The physicians who reported receiving requests from patients for unnecessary tests or procedures more frequently were those who acknowledged either ordering tests (every day or almost every day) for them or carrying out unnecessary procedures themselves for patients $\left(\mathrm{x}^{2}=419.0, \mathrm{P}<0.001, \mathrm{PD}=16.8\right)$. They also stated that the reaction by the patient (or guardian) when a request for tests or procedures was denied was more negative or aggressive $\left(\mathrm{x}^{2}=247.7, \mathrm{P}<0.001, \mathrm{PD}=20.1\right)$.

Male nurses, compared with their female counterparts, reported greater pressure from patients to carry out unnecessary procedures $\left(\mathrm{x}^{2}=14.8, \mathrm{P}=0.005, \mathrm{PD}=12.7\right)$ and, compared with the female nurses, carried out these unnecessary procedures more frequently $\left(\mathrm{x}^{2}=14.1\right.$, $\mathrm{P}=0.007, \mathrm{PD}=10.2)$. The ability to dissuade patient requests was similar in men and women in all three professional profiles. However, male nurses, compared with female, reported receiving an aggressive response more frequently $\left(\mathrm{x}^{2}=13.6, \mathrm{P}=0.009, \mathrm{PD}=11.1\right)$.

Paediatricians with less than 5 years of experience reported receiving requests for unnecessary tests or procedures most frequently $\left(\mathrm{x}^{2}=52.6, \mathrm{P}<0.001, \mathrm{PD}=21.3\right)$. Paediatricians who had practised fewer years stated that 


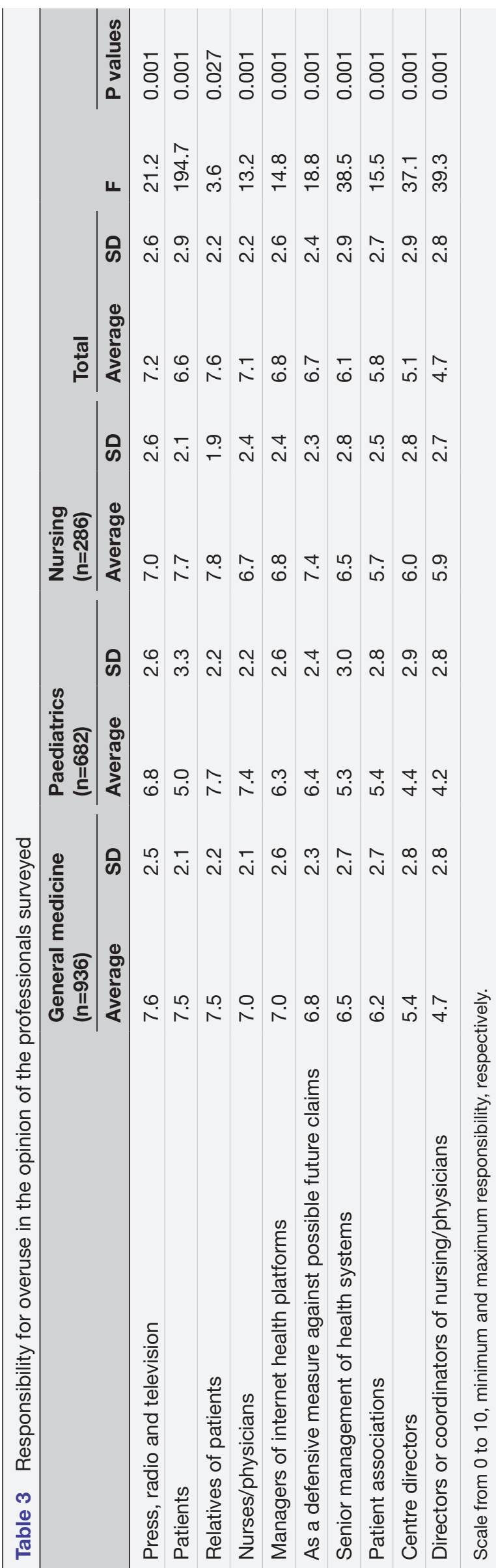

when refusing a patient's request, the patient's reaction was frequently more negative or even aggressive in comparison to their more experienced colleagues $\left(\mathrm{x}^{2}=68.4, \mathrm{P}<0.001, \mathrm{PD}=6.5\right)$.

\section{What patients request}

The most frequent requests from patients were for routine analytical examinations, referrals to specialists, antimicrobial treatments, radiological studies and requests for healing materials without indication (table 5). The profile of the patient who requested unnecessary nursing procedures the most corresponded to that of a woman $(145,50.7 \%)$ over 66 years of age $(158,55.2 \%)$ who suffered various chronic conditions $(154,53.8 \%)$. In the case of general practitioners, these were usually women $(604,64.5 \%)$ between 51 years and 65 years of age $(411$, $43.9 \%$ ) with a low prevalence pathology $(296,31.6 \%)$ or one that was unspecified $(219,23.4 \%)$ and who consulted the internet about their concerns $(172,18.4 \%)$. In paediatrics, the profile of the guardian who most persistently requested unnecessary tests or procedures corresponded to the mother of a patient $(480,70.4 \%)$ who suffered an unspecified pathology $(367,53.8 \%)$ and who usually sought information on health web pages $(130,19.1 \%)$.

\section{Ideas that work to dissuade the patient}

According to the majority of those surveyed, the arguments that worked best for dissuading the patient or guardian that the request was inadequate were clinical reasons and patient safety (table 6 ). The safety of the child $\left(\mathrm{x}^{2}=31.7, \mathrm{P}<0.001, \mathrm{PD}=8.5\right)$ and avoiding discomfort to the child $\left(\mathrm{x}^{2}=57.7, \mathrm{P}<0.001, \mathrm{PD}=10.0\right)$ were considered more effective arguments above all for paediatricians. Cost savings was the least effective argument for paediatricians $\left(\mathrm{x}^{2}=43.9, \mathrm{P}<0.001, \mathrm{PD}=6.9\right)$, while avoiding patient discomfort was least effective for general practitioners $\left(\mathrm{x}^{2}=57.7, \mathrm{P}<0.001\right)$. For more experienced paediatricians $\left(\mathrm{x}^{2}=30.6, \mathrm{P}=0.002, \mathrm{PD}=17.0\right)$ and nurses $\left(\mathrm{x}^{2}=23.6\right.$, $\mathrm{P}=0.023, \mathrm{PD}=28.8)$, arguing clinical reasons to dissuade the patient or guardian's request worked better.

Paediatricians were more successful than general practitioners and nurses at dissuading their patients that the requested test or procedure was unnecessary or that it posed unnecessary risk $\left(\mathrm{x}^{2}=45.0, \mathrm{P}<0.001, \mathrm{PD}=5.4\right)$. Nurses reported more frequently that the patient's reaction to a request being refused due to being unnecessary was either negative or aggressive $\left(\mathrm{x}^{2}=129.5, \mathrm{P}<0.001\right.$, $\mathrm{PD}=14.4)$. Men and women from all three professional profiles expressed a similar ability for dissuading a patient's request. Less experienced paediatricians stated they were able to dissuade patients more frequently than other paediatricians $\left(\mathrm{x}^{2}=23.9, \mathrm{P}=0.021, \mathrm{PD}=12.4\right)$.

Patients who requested healing materials to take home $\left(24 / 48, \mathrm{x}^{2}=15.2, \mathrm{P}=0.004, \mathrm{PD}=14.4\right)$, vaccinations outside the vaccine calendar $\left(11 / 34, \mathrm{x}^{2}=10.1, \mathrm{P}=0.039\right.$, $\mathrm{PD}=14.5)$ and antibiotic treatments $\left(31 / 491, \mathrm{x}^{2}=33.4\right.$, $\mathrm{P}<0.001, \mathrm{PD}=4.2$ ) were those who, in the opinion of the 
Table 4 Pressure from patients and response by professionals

\begin{tabular}{|c|c|c|c|c|c|}
\hline & $\begin{array}{l}\text { Patients (or their } \\
\text { guardians) request } \\
\text { unnecessary tests } \\
\text { and procedures } \\
\text { from you }\end{array}$ & $\begin{array}{l}\text { You order/carry } \\
\text { out unnecessary } \\
\text { tests or procedures } \\
\text { due to pressure } \\
\text { from a patient (or } \\
\text { guardian) }\end{array}$ & $\begin{array}{l}\text { You convince } \\
\text { the patient (or } \\
\text { guardian) that it } \\
\text { is unnecessary } \\
\text { and can pose } \\
\text { significant risk }\end{array}$ & $\begin{array}{l}\text { The patient's } \\
\text { response is } \\
\text { negative, or } \\
\text { even aggressive, } \\
\text { when you refuse } \\
\text { to carry out } \\
\text { a procedure } \\
\text { that the patient } \\
\text { requests from you }\end{array}$ & \\
\hline & $\mathbf{N}(\%)$ & N (\%) & N (\%) & N (\%) & \\
\hline \multicolumn{6}{|c|}{ General practitioners $(n=936)$} \\
\hline Never & $12(1.3)$ & $118(12.6)$ & $55(5.9)$ & $237(25.3)$ & Never \\
\hline Monthly & $192(20.5)$ & $463(49.5)$ & $248(26.5)$ & $400(42.7)$ & Sometimes \\
\hline Every day & $76(8.1)$ & $15(1.6)$ & $50(5.3)$ & $39(4.2)$ & All the time \\
\hline \multicolumn{6}{|c|}{ Paediatricians $(\mathrm{n}=682)$} \\
\hline Never & $9(1.3)$ & $188(27.6)$ & $14(2.1)$ & $231(33.9)$ & Never \\
\hline Monthly & $228(33.4)$ & $401(58.8)$ & $182(26.7)$ & $343(50.3)$ & Sometimes \\
\hline $\begin{array}{l}\text { Almost every } \\
\text { week }\end{array}$ & $316(46.3)$ & $84(12.3)$ & $262(38.4)$ & $73(10.7)$ & Half the time \\
\hline $\begin{array}{l}\text { Almost every } \\
\text { day }\end{array}$ & $113(16.6)$ & $6(0.9)$ & $188(27.6)$ & $30(4.4)$ & Most of the time \\
\hline Every day & $16(2.3)$ & $3(0.4)$ & $36(5.3)$ & $5(0.7)$ & All the time \\
\hline Every day & $11(3.8)$ & $8(2.8)$ & $8.0(2.8)$ & $2(0.7)$ & All the time \\
\hline
\end{tabular}

professionals surveyed, were least willing to accept explanations and refusals by the professionals for their request.

According to 1231 (64.7\%) of those surveyed, an educational campaign directed at the population would help reduce the number of requests for unnecessary tests and procedures by patients. Such a campaign was seen as most useful by general practitioners (general practitioners, 8.0, SD 2.1, $95 \%$ CI 7.9 to 8.0; paediatricians, 7.7, SD 2.0, 95\% CI 7.6 to 7.9 ; nurses, 7.7 , SD 2.0; $95 \%$ CI 7.6 to 7.8 ).

\section{DISCUSSION}

The results of this study confirm the role that patients' requests and defensive medicine play in overuse. In this study, health professionals reported greater pressure from female patients and patients who suffer an unspecified or yet-undiagnosed pathology. For the former group, and in order to interpret this result, it needs to be taken into consideration that in many European countries women frequently accompany the patient to the consultation (adult or minor). ${ }^{31}$ As for the latter case, one needs to consider that in addition to the fears the patient experiences due to the uncertainty of not knowing what is happening to him/her, there is added pressure from family members, the effect from consulting health news on the internet, and news from the printed and digital media about medical advances and new techniques.

In this case, it has been proven that overuse also has roots in the insecurity that an ill-defined pathology instils within the professional, the fear of an uncertain outcome for the indicated treatment, as well as the potential effects from a subsequent complaint by the patient or a lawsuit filed in a court of law. The lack of a diagnosis, the lack of time in consultation, and the need for greater security in the diagnosis are another of the main causes of overuse. ${ }^{31}$ 
Table 5 Unnecessary tests and procedures patients usually request

\begin{tabular}{|c|c|c|c|c|c|}
\hline $\begin{array}{l}\text { General practitioners } \\
(\mathrm{n}=936)\end{array}$ & N (\%) & Paediatricians $(n=682)$ & N (\%) & Nurses $(n=286)$ & N (\%) \\
\hline $\begin{array}{l}\text { Routine check-up } \\
\text { analysis }\end{array}$ & 709 (75.7) & $\begin{array}{l}\text { Routine check-up } \\
\text { analysis }\end{array}$ & $510(74.8)$ & Taking vital signs & $225(78.7)$ \\
\hline $\begin{array}{l}\text { Referrals to specialists } \\
\text { without any concerning } \\
\text { features* }\end{array}$ & $628(67.1)$ & $\begin{array}{l}\text { Administration of } \\
\text { antibiotics when it is } \\
\text { not recommended* }\end{array}$ & $491(72.0)$ & $\begin{array}{l}\text { Administration of treatment } \\
\text { that does not require } \\
\text { professionals }\end{array}$ & $175(61.2)$ \\
\hline $\begin{array}{l}\text { MR without any } \\
\text { concerning features* }\end{array}$ & $380(40.6)$ & $\begin{array}{l}\text { Radiological studies } \\
\text { without any concerning } \\
\text { features* }\end{array}$ & 197 (28.9) & $\begin{array}{l}\text { Delivery of glucometer } \\
\text { without the patient having } \\
\text { started hypoglycaemia } \\
\text { treatment }\end{array}$ & $72(25.2)$ \\
\hline $\begin{array}{l}\text { Administration of } \\
\text { antibiotics when it is not } \\
\text { recommended* }\end{array}$ & $348(37.2)$ & & & & \\
\hline $\begin{array}{l}\text { CT when it is not } \\
\text { recommended }\end{array}$ & 280 (29.9) & & & & \\
\hline \multicolumn{6}{|c|}{$\begin{array}{l}\text { ^Following Do not DO Recommendations from the Grupo de trabajo de la Sociedad Española de Medicina Familiar y Comunitaria (SEMFyC) } \\
\text { para el proyecto Recomendaciones. Recomendaciones NO HACER. Barcelona: SEMFyC ediciones, 2014, and the Asociación Española de } \\
\text { Pediatría (AEP). Recomendaciones de 'no hacer' en Pediatría. } 2014 \text { (accessed } 24 \text { Jun 2017): Available in: http://www.aeped.es/documentos, } \\
\text { recomendaciones-no-hacer-en-pediatria } \\
\text { PSA, prostate-specific antigen. }\end{array}$} \\
\hline
\end{tabular}

Curiously enough, these results show that as requests from patients become more insistent, for example, vaccinating a minor outside the vaccine calendar, an antibiotic when it is contraindicated or giving healing materials to the patient so he/she can take them home, the response from these patients is more negative. Both of these results could support the opinions of those surveyed about the usefulness of carrying out an educational campaign among the population ${ }^{32}$ and the measures that have been adopted to prevent aggression towards professionals.

Previous research had found that, when compared with other specialties, general practitioners were under greater pressure by their patients for unnecessary medical tests or procedures to be carried out on them. ${ }^{33}$ The fact

Table 6 Degree of effectiveness as reported by the professionals about the arguments for convincing the patient that the treatment or procedure is unnecessary

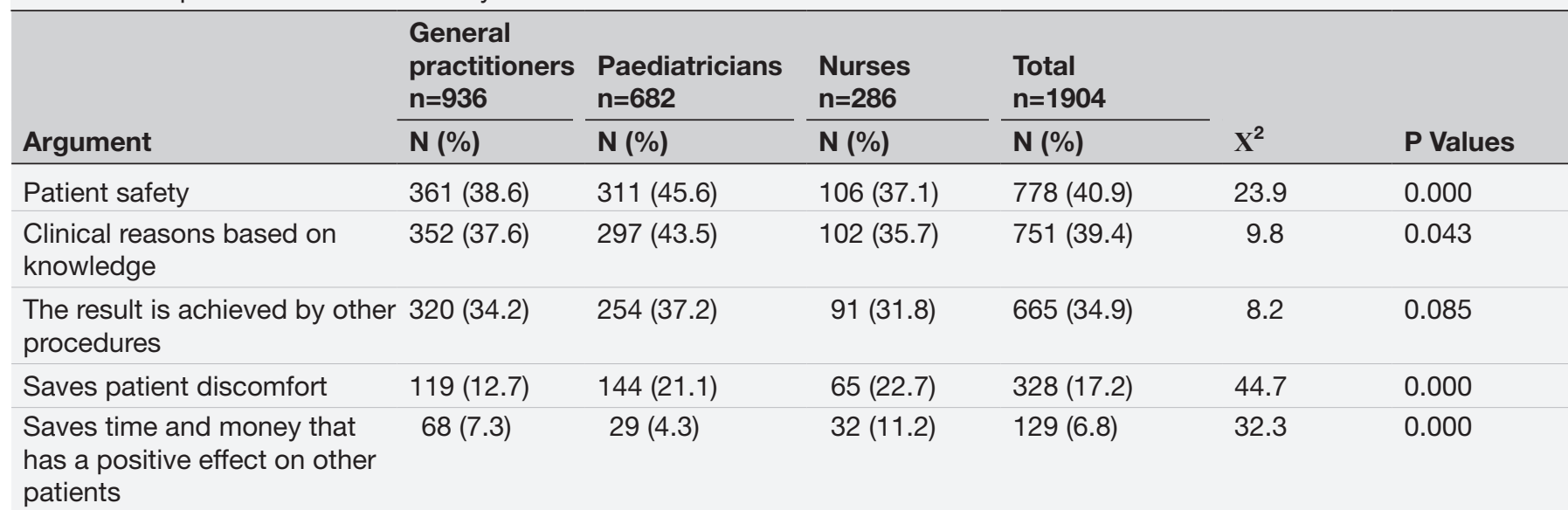

High and Very High degrees of effectiveness shown. 
that patients in primary care exert greater pressure than in hospitals is observed in both organisational models of payment for medical acts as well as in systems where the physician is the gatekeeper. ${ }^{27} 33$ These results should be interpreted keeping in mind the assessment patients give about care levels in every country and the belief that super specialisation might be a key to quality medicine.

The frequency of requests for medical tests or procedures in the study by Zambrana and Lozano ${ }^{35}$ in Spanish hospitals exceeded the frequency of requests that physicians in American hospitals reported by 16 percentage points. In this study in primary care, the frequency that general practitioners said they receive requests from their patients was 38 percentage points higher than what American physicians reported ( $78 \%$ vs $40 \%$ ). The tendency of published figures of overuse from organisational models of primary care similar to that of the Spanish model ${ }^{27}$ point to a similar direction, and suggests the gatekeepers need support to prevent (or at least reduce) overuse. Moreover, this debate remains open because other studies conducted in the USA ${ }^{34}$ indicate that overuse in the wake of patient requests is similar at health centres in both wealthy areas and areas with lower income levels.

This study's findings reveal that as perceived pressure from patients becomes more insistent, the professionals either order or carry out a greater number of unnecessary tests and procedures, extending the initial observations that general practitioners tend to accept requests from their patients more so than other specialists. ${ }^{34}$ General practitioners perceive more pressure from their patients than paediatricians or nurses, although the latter are those who carry out unnecessary procedures more frequently, probably because this group acknowledges being on the receiving end of more aggressive responses from patients when turning down requests. Nevertheless, these results should be qualified based on the request the patient makes and by the dissemination of practice guides between professionals. It is unlikely that ordering a test such as the prostate-specific antigen test (PSA) in an asymptomatic male patient who insists so he can 'rest easy' is the same as initiating a totally contraindicated treatment and one that poses immediate risks for the patient. Most physicians accept the first situation more easily, ${ }^{36}$ but resist the second. ${ }^{23} 31$

Although professionals are directly responsible for overuse, and this and other research recognise this as such, ${ }^{2733}$ we must also consider the role that patient associations, accreditation systems of websites and associations of health news informers could play a role to succeed, among everybody, in reducing overuse figures. Ignorance on behalf of the population has been analysed in other research, especially that regarding the use of therapies and requests for diagnostic imaging tests irrespective of the risk from the ionising radiation involved. ${ }^{37}$

Information does not always contribute to fulfil these recommendations. ${ }^{26}$ However, providing the patient with clear and direct information about the clinical and safety reasons that advise against carrying out certain tests or starting certain treatments contributes to reducing overuse. ${ }^{389}$ These results follow this line and confirm findings from research conducted in other countries where primary care physicians draw on evidence to dissuade a patient's request for a certain diagnostic test when they deem it unnecessary. ${ }^{23}$ The other argument that has also demonstrated its usefulness for dissuading the patient is safety, above all for paediatricians. Considering the Spanish study with hospital physicians, ${ }^{35}$ the effectiveness of general practitioners and paediatricians in dissuading patients is similar to that of their colleagues at hospitals. The paediatricians in this study did not report a dissuasive capacity any different from that of their colleagues who care for adults.

Professionals who fail to dissuade patients from their requests feel as if they are under great pressure and end up carrying out more unnecessary tests and procedures, and they also perceive more aggressive responses from their patients when refusing to carry out any of their requests. Although we do know that the lack of time in consultation has a negative effect on clinical safety, ${ }^{32}$ these data do not permit us to determine whether the ability to dissuade patients from their requests might be different if more time were dedicated per patient. For a significant portion of physicians, and for those surveyed in this study as well, maintaining a positive relationship with the patient was essential, ${ }^{25} 27$ probably because it is one of the basic therapeutic resources in primary care. ${ }^{40}$ Not responding to a request or not knowing how to dissuade the patient muddies the relationship. Furthermore, when the patient questions the physician's clinical expertise, their relationship worsens and defensive medicine tends to increase. ${ }^{48}$

The frequency of overuse resulting from movements grouped together under the 'Less is More Medicine' label $^{41}$ has begun to be studied systematically, and various campaigns have been launched to raise awareness in professionals about what must not be done, ${ }^{42-44}$ but studies analysing the roles of patients and professionals in overuse and the impact from campaigns to reduce overuse directed at the population are still scarce. Furthermore, campaigns for reducing overuse in the style of Choosing Wisely ${ }^{44}$ confirm the need to influence health education, and are directed especially at drawing attention to the risks from interpreting health websites without the appropriate information, like, for example, considering their latest update, sources of information, and the commitment to the quality of their contents, ${ }^{45}$ and reducing the negative impact that these sources of information are beginning to have on the relationship between patients and professionals. ${ }^{146}{ }^{46}$ This is also true in the case of publicly financed health systems, to carry out campaigns to fortify solidarity behaviour and to properly use diagnostic and therapeutic resources.

\section{Practical implications}

These results have direct implications on the professional level. First, fostering training in communication skills, 
highlighting how to approach communication with a patient who applies pressure to receive an unnecessary and/or harmful test or treatment for him or herself. For example, by promoting the so-called web prescription by recommending safe sites to patients where they can become informed, an aspect in which Spain lags somewhat behind. ${ }^{46}$ Second, establishing a framework of greater legal security for professionals who act in accordance with practice guides. Third, identifying if Do not Do has a higher chance to produce an adverse event to define it as a target in a public campaign to reduce patients' requests.

On the health organisation level, these results reinforce the need to establish the implementation in primary care of up-to-date practice guides and to establish alerts and assistance algorithms (including safety arguments for patients) on the ordering of tests, referrals and prescriptions for limiting overuse. The lessons learnt using decision aids to reduce more aggressive choices could be applied to design these algorithms. ${ }^{47}$ Management indicators and annual or biennial targets could include indicators related to overuse, especially in those cases where, furthermore, the risk to patient safety increases.

\section{Generalisability}

These results and recommendations could be applied to the healthcare systems where the general practitioners (or paediatricians in the case of children) are the gatekeepers.

\section{Limitations}

This study was based on a non-random selection of participants. This sample included approximately $3 \%$ of the general practitioners, $11 \%$ of the paediatricians and $1 \%$ of the nurses in terms of the total of healthcare professionals in Spanish primary care in 2016. Studies using email and electronic questionnaires are frequent; however, some professionals might have considered that these systems would not guarantee their privacy and so decided not to answer. The willingness to respond could bias the sample selection, and in some other cases physicians or nurses might not admit to overuse. Although the public sector is over-represented, this over-representation is also observed in the reference population. The limited number of men who answered in the cases of paediatrics and nursing limits the strengths of the comparisons, even though their number is proportional to that of their presence within these professional groups. The data correspond to a health model funded by taxes. Although the questionnaire was used in a previous study, ${ }^{12}$ it has not been previously validated. This quantitative approach should be complemented with qualitative studies exploring experiences and coping styles to avoid overuse.

\section{Outlook}

Overuse is a challenge for health systems, particularly those where the general practitioner is the system gatekeeper, and it requires responses from both the clinical as well as economic points of view.

\section{Author affiliations}

${ }^{1}$ Alicante-Sant Joan Health District, Conselleria de Sanidad, Alicante, Spain

${ }^{2}$ Health Psychology Department, Universidad Miguel Hernández de Elche, Alicante, Spain

${ }^{3}$ REDISSEC, Red de Servicios de Salud Orientados a Enfermedades Crónicas,

Valencia, Spain

${ }^{4}$ Servicio de Efectividad y Seguridad Asistencial, Servicio Navarro de Salud-

Osasunbidea, Pamplona, Spain

${ }^{5}$ Observatorio para la Seguridad del Paciente, Agencia de Calidad Sanitaria de Andalucía, Sevilla, Spain

${ }^{6}$ Centro de Salud Fuente de San Luis, Dr. Peset Health District, Conselleria de Sanidad, Valencia, Spain

${ }^{7}$ Hospital Clínico San Carlos, Servicio Madrileño de Salud, Madrid, Spain

${ }^{8}$ Hospital General Universitario de Alicante, Conselleria de Sanidad, Alicante, Spain

${ }^{9} \mathrm{CIBER}$ de Enfermedades Raras, Alicante, Spain

${ }^{10}$ Hospital Universitario Ramón y Cajal, Instituto Ramón y Cajal de Investigación

Sanitaria (IRYCIS), Servicio Madrileño de Salud, Madrid, Spain

${ }^{11}$ Centro de Investigación Biomédica en Red en Epidemiología y Salud Pública (CIBERESP), Madrid, Spain

Contributors JJM and JMAA conceived and designed the study. CS, PP-P, CN, GO and $\mathrm{JGnD}$ acquired the data for the work. IC prepared the data, and together with JJM and JMAA, conducted statistical analysis. All authors interpreted data for the work. JJM and IC prepared the first draft of the manuscript. All authors revised the paper critically for important intellectual content and approved the final version.

Funding This study received a grant from the Instituto de Salud Carlos III (Spanish Health Research Fund), and the European Regional Development Fund/European Social Fund (ERDF/ESF) call for Health Research, reference PI16/00816.

Competing interests None declared.

Patient consent Not required.

Ethics approval This study was assessed and approved by the Ethics Committee of Primary Care Research of the Valencian Community, Spain.

Provenance and peer review Not commissioned; externally peer reviewed.

Data sharing statement № additional data are available.

Open access This is an open access article distributed in accordance with the Creative Commons Attribution Non Commercial (CC BY-NC 4.0) license, which permits others to distribute, remix, adapt, build upon this work non-commercially, and license their derivative works on different terms, provided the original work is properly cited and the use is non-commercial. See: http://creativecommons.org/ licenses/by-nc/4.0/

(C) Article author(s) (or their employer(s) unless otherwise stated in the text of the article) 2018. All rights reserved. No commercial use is permitted unless otherwise expressly granted.

\section{REFERENCES}

1. Lainer M, Vögele A, Wensing M, et al. Improving medication safety in primary care. A review and consensus procedure by the LINNEAUS collaboration on patient safety in primary care. Eur J Gen Pract 2015;21(Suppl):14-18.

2. Hatoun J, Chan JA, Yaksic E, et al. A systematic review of patient safety measures in adult primary care. Am J Med Qual 2017;32:237-45.

3. Glasziou P, Straus S, Brownlee S, et al. Evidence for underuse of effective medical services around the world. Lancet 2017;390:169-77.

4. Morgan DJ, Wright SM, Dhruva S. Update on medical overuse. JAMA Intern Med 2015;175:120-4.

5. Chassin MR, Galvin RW. The urgent need to improve health care quality. Institute of Medicine National Roundtable on Health Care Quality. JAMA 1998;280:1000-5.

6. Brownlee S, Chalkidou K, Doust J, et al. Evidence for overuse of medical services around the world. Lancet 2017;390:156-68.

7. Schoen C, Osborn R, Squires D, et al. A survey of primary care doctors in ten countries shows progress in use of health information technology, less in other areas. Health Aff 2012;31:2805-16. 
8. Panella M, Leigheb F, Rinaldi C, et al. [Defensive medicine: defensive medicine: overview of the literature]. Ig Sanita Pubb/ 2015;71:335-51.

9. Selby K, Cornuz J, Cohidon C, et al. How do Swiss general practitioners agree with and report adhering to a top-five list of unnecessary tests and treatments? Results of a cross-sectional survey. Eur J Gen Pract 2018;24:1.

10. Sirovich BE, Woloshin S, Schwartz LM. Too Little? Too Much? Primary care physicians' views on US health care: a brief report. Arch Intern Med 2011;171:1582-5.

11. Perry Undem Research/Communication. Unnecessary tests and procedures in the health care system: what physicians say about the problem, the causes, and the solutions: results from a national survey of physicians: ABIM Foundation, 2014

12. Cummins $R O$. Clinicians' reasons for overuse of skull radiographs. AJR Am J Roentgenol 1980;135:549-52.

13. Tilburt JC, Wynia MK, Sheeler RD, et al. Views of US physicians about controlling health care costs. JAMA 2013;310:380-8.

14. Mira JJ, Guilabert M, Pérez-Jover V, et al. Barriers for an effective communication around clinical decision making: an analysis of the gaps between doctors' and patients' point of view. Health Expect 2014:17:826-39.

15. Buist DS, Chang E, Handley M, et al. Primary care clinicians' perspectives on reducing low-value care in an integrated delivery system. Perm J 2016;20:41-6.

16. Freudenberg LS, Beyer T. Subjective perception of radiation risk. $J$ Nucl Med 2011;52(Suppl 2):29S-35.

17. Kruger JF, Chen AH, Rybkin A, et al. Clinician perspectives on considering radiation exposure to patients when ordering imaging tests: a qualitative study. BMJ Qual Saf 2014;23:893-901.

18. Diaz JA, Griffith RA, Ng JJ, et al. Patients' use of the Internet for medical information. J Gen Intern Med 2002;17:180-5.

19. Mira Solves JJ, Llinás Santacreu G, Lorenzo Martínez S, et al. Uso de internet por médicos de primaria y hospitales y percepción de cómo influye en su relación con los pacientes. Atención Primaria 2009;41:308-14

20. Silverstein W, Lass E, Born $\mathrm{K}$, et al. A survey of primary care patients readiness to engage in the de-adoption practices recommended by Choosing Wisely Canada. BMC Res Notes 2016;9:301.

21. Cohen O, Kahan E, Zalewski S, et al. Medical investigations requested by patients: how do primary care physicians react? Fam Med 1999;31:426-31.

22. Yagil D, Medler-Liraz H. Clinical expert or service provider? Physicians' identity work in the context of counterprofessional patient requests. Qual Health Res 2015;25:1199-211.

23. Fenton JJ, Franks P, Feldman MD, et al. Impact of patient requests on provider-perceived visit difficulty in primary care. $J$ Gen Intern Med 2015;30:214-20.

24. Sabbatini AK, Tilburt JC, Campbell EG, et al. Controlling health costs: physician responses to patient expectations for medical care. $J$ Gen Intern Med 2014;29:1234-41.

25. Alber K, Kuehlein T, Schedlbauer A, et al. Medical overuse and quaternary prevention in primary care - A qualitative study with general practitioners. BMC Fam Pract 2017;18:99.

26. Zikmund-Fisher BJ, Kullgren JT, Fagerlin A, et al. Perceived barriers to implementing individual choosing wisely ${ }^{\circledR}$ recommendations in two national surveys of primary care providers. J Gen Intern Med 2017;32:210-7.

27. Wammes JJ, Jeurissen PP, Verhoef LM, et al. Is the role as gatekeeper still feasible? A survey among Dutch general practitioners. Fam Pract 2014;31:538-44.

28. Ministerio de Sanidad. La salud y el sistema sanitario en 100 tablas. https://www.msssi.gob.es/estadEstudios/estadisticas/sisInfSanSNS/
tablasEstadisticas/SaludSistemaSanitario_100_Tablas1.pdf (accessed 26 Jun 2017).

29. Domínguez-Aurrecoechea B, Valdivia-Jiménez C. Radiografía de la pediatría de atención primaria española: nuestro espacio en el sistema nacional de salud. Rev Pediatr Aten Primaria 2011;13:59-70.

30. Ministerio de Sanidad, Servicios Sociales e Igualdad. SIAP Estadísticas de Población, Recursos y Actividad. Aplicación interactiva, año. 2016 http://pestadistico.inteligenciadegestion.msssi. es/publicoSNS/comun/Cubo.aspx? IdNodo = 6407\#no-back-button (accessed 31 Jul 2017).

31. Moro ML, Marchi M, Gagliotti C, et al. Why do paediatricians prescribe antibiotics? Results of an Italian regional project. BMC Pediatr 2009;9:69.

32. Mira JJ, Nebot C, Lorenzo S, et al. Patient report on information given, consultation time and safety in primary care. Qual Saf Health Care 2010;19:e33.

33. Colla CH, Kinsella EA, Morden NE, et al. Physician perceptions of Choosing Wisely and drivers of overuse. Am J Manag Care 2016;22:337-43.

34. Kaul S, Kirchhoff AC, Morden NE, et al. Physician response to patient request for unnecessary care. Am J Manag Care 2015;21:823-32.

35. Zambrana-García JL, Lozano Rodríguez-Mancheño A. Actitudes de los médicos hacia el problema de las pruebas y los procedimientos innecesarios. Gac Sanit 2016;30:485-6.

36. Jessen K, Søndergaard J, Larsen PV, et al. Danish general practitioners' use of prostate-specific antigen in opportunistic screening for prostate cancer: a survey comprising 174 GPs. Int J Family Med 2013;2013:1-6.

37. Griffith J, Monkman H, Borycki E, et al. Physician experiences with perceived pressure to order diagnostic imaging services. Stud Health Technol Inform 2015;218:40591.

38. Schoenthaler A, Albright G, Hibbard J, et al. Simulated conversations with virtual humans to improve patient-provider communication and reduce unnecessary prescriptions for antibiotics: a repeated measure pilot study. JMIR Med Educ 2017;3:e7

39. Légaré $\mathrm{F}$, Labrecque $\mathrm{M}, \mathrm{Cauchon} \mathrm{M}$, et al. Training family physicians in shared decision-making to reduce the overuse of antibiotics in acute respiratory infections: a cluster randomized trial. CMAJ 2012;184:E726-34

40. Mira JJ, Martínez-Jimeno L, Orozco-Beltrán D, et al. What older complex chronic patients need to know about their everyday medication for safe drug use. Expert Opin Drug Saf 2014;13:1-9.

41. Rosenberg A, Agiro A, Gottlieb M, et al. Early trends among seven recommendations from the choosing wisely campaign. JAMA Intern Med 2015;175:1913-20.

42. Combs B, Caverly T. The do no harm project. 2014; school of medicine, internal medicine residency training program, University of Colorado. https://lowninstitute.org/wp-content/uploads/2014/ 05/The-Do-No-Harm-Project-Intro-Slides.pdf (accessed 9 Jun 2017).

43. Bonaldi A, Vernero S. [Italy's Slow medicine: a new paradigm in medicine]. Recenti Prog Med 2015;106:85-91.

44. ABIM Foundation. Choosing Wisely. http://www.choosingwisely.org/ (accessed 24 Jun 2017).

45. Mira JJ, Llinás G, Pérez-Jover V. Habits of Internet users and usefulness of websites in Spanish for health education. World Hosp Health Serv 2008;44:30-5.

46. Lorenzo S, Mira JJ. Are Spanish physicians ready to take advantage of the Internet? World Hosp Health Serv 2004;40:31-5.

47. Stacey D, Légaré F, Lewis K, et al. Decision aids for people facing health treatment or screening decisions. Cochrane Database Syst Rev 2017;4:CD001431. 